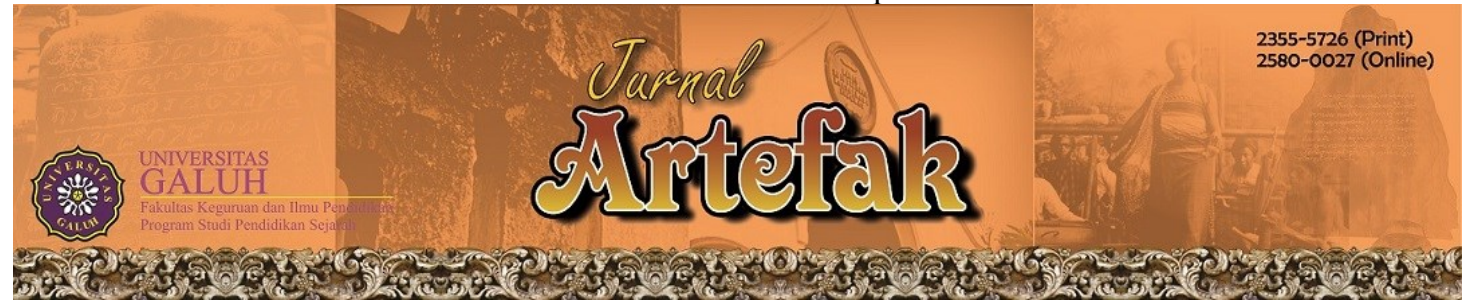

https://jurnal.unigal.ac.id/index.php/artefak/article/view/4951

\title{
MENGKAJI MANFAAT DAN NILAI-NILAI DALAM PELAKSANAAN TRADISI SEDEKAH BUMI DARI SUDUT PANDANG TEORI FUNGSIONALISME
}

\author{
Martin Rizaldi ${ }^{1}$, Anin Lailatul Qodariyah ${ }^{2}$ \\ ${ }_{1,2}$ Universitas Negeri Malang, Indonesia \\ E-mail: rizaldimartin158@gmail.com 1, aninlailatul@gmail.com ${ }^{2}$ \\ Sejarah Artikel: Diterima 1-Maret-2021 Disetujui 15-Maret-2021 Dipublikasikan -April-2021
}

\begin{abstract}
Abstrak
Artikel ini bertujuan untuk memahami manfaat nilai-nilai dalam pelaksanaan tradisi sedekah bumi dari sudut pandang teori fungsionalisme. Metode yang digunakan dalam proses pengumpulan data pada penulisan artikel ini dilakukan dengan menelaah dan mengeksplorasi beberapa buku, jurnal, dan dokumen, baik cetak maupun elektronik yang dianggap relevan dengan kajian yang dilakukan. Di Indonesia banyak sekali macam-macam tradisi salah satunya yaitu tradisi sedekah bumi adalah suatu tradisi berupa perayaan adat yang ditujukan pada bumi sebagai bentuk rasa syukur masyarakat atas keselamatan yang diberikan oleh sang maha pencipta. Dalam tradisi sedekah bumi terdapat berbagai ritual kegiatan yang dilakukan, serta didalamnya terkandung manfaat dan nilai-nilai yang dapat dikaji dengan teori fungsionalisme seperti nilai akidah, nilai ibadah, nilai sosial, nilai budaya, dan nilai filosofis.
\end{abstract}

Kata Kunci: Nilai-nilai, Teori fungsionalisme, Tradisi Sedekah Bumi

This article aims to understand the benefits of values in the implementation of the earth alms tradition from the point of view of the theory of functionalism. The method used in the data collection process in writing this article was carried out by examining and exploring several books, journals, and documents, both printed and electronic, which were considered relevant to the study carried out. In Indonesia, there are many kinds of traditions, one of which is the earth alms tradition, which is a tradition in the form of traditional celebrations aimed at the earth as a form of public gratitude for the salvation given by the Almighty Creator. In the earth alms tradition, there are various ritual activities carried out, and there are benefits and values that can be studied with functionalism theories such as faith values, worship values, social values, cultural values, and philosophical values.

Keyword: Values, Functionalisme theory, Alms tradition

\section{PENDAHULUAN}

Di Indonesia terdapat beragam kebudayaan diberbagai penjuruh wilayahnya, kebudayaan yang beragam masih kental dengan tradisi-tradisi kuno yang dilakukan secara turun temurun. Selain itu tradisi-tradisi tersebut masih dijunjung tinggi dan dilestarikan oleh masyarakat sebagai peninggalan nenek moyang. Tradisi merupakan suatu kebiasaan yang telah ada sejak zaman dahulu dan dilaksanakan secara turun-temurun. Salah satunya, tradisi yang masih ada dan masih terus dilestarikan oleh masyarakat sampai saat ini khususnya masyarakat Pulau Jawa adalah tradisi sedekah bumi. Tradisi ini berlangsung setiap tahun saat musim panen dengan hari yang telah ditentukan oleh petinggi adat didaerahnya.

Berdasarkan sejarah budaya Jawa, pada awalnya pelaksanaan tradisi seodekah bumi merupakan upacara sebagai bentuk pemujaan 
atau penghormatan kepada roh nenek moyang. Sedangkan, menurut orang Jawa-Hindu sedekah bumi dianggap sebagai upaya pemujaan kepada Dewi Sri atau dewa kesuburan. Sementara itu, menurut Hidayatulloh (2015) dalam artikelnya yang dimaksud tradisi sedekah bumi adalah sebuah perayaan adat yang ditujukan pada bumi sebagai bentuk rasa syukur dan wujud terima kasih masyarakat pada sang penciptanya yang memberi keselamatan dan tempat tinggal. Masyarakat tersebut melakukan suatu hal sedekah bumi karena bagi mereka itu merupakan hal yang perlu dilakukan dalam bentuk mewujudkan rasa terima kasih dan bentuk syukur atas keselamatan dan rejeki yang diberikan oleh bumi karena telah menjadi tempat tinggal bagi masyarakat tersebut.

Dari uraian diatas penulis tertarik untuk mengkaji tradisi sedekah bumi dengan menarik tiga rumusan masalah yaitu (1) Apa yang dimaksud pengertian dari tradisi sedekah bumi. (2) Bagaimana pelaksanaan tradisi sedekah bumi. (3) Apa saja manfaat dan nilainilai tradisi sedekah bumi dari sudut pandang teori fungsionalisme. Dengan tiga rumusan masalah tersebut diharapkan mampu untuk menjawab ketertarikan penulis tentang tradisi sedekah bumi. Artikel ini bertujuan untuk mengetahui pengertian dari tradisi sedekah bumi, untuk mengetahui pelaksanaan tradisi sedekah bumi, dan untuk mengetahui manfaat dan nilai-nilai tradisi sedekah bumi dari sudut pandang teori fungsionalisme.

\section{METODE PENELITIAN}

Metode penyusunan artikel ini menggunakan metode kajian pustaka atau studi Pustaka menggunakan instrumen studi dokumen. Menurut Setyosari (2016) yang dimaksud dengan metode kajian pustaka adalah metode penelitian yang menggunakan sumber referensi dari buku dan jurnal. Sedangkan menurut Nazir (1988) Sehingga berdasarkan uraian tersebut, metode yang digunakan dalam proses pengumpulan data pada penulisan artikel ini dilakukan dengan menelaah dan mengeksplorasi beberapa buku, jurnal, dan dokumen, baik cetak maupun elektronik yang dianggap relevan dengan kajian yang dilakukan.

\section{HASIL PENELITIAN DAN PEMBAHASAN}

\section{Pengertian Tradisi Sedekah Bumi}

Tradisi sedekah bumi adalah suatu kegiatan berupa selamatan dan dianggap bahwa kegiatan itu sebagai upaya mewujudkan rasa syukur yang dilaksanakan setelah melakukan kegiatan panen. Kata sedekah mempunyai makna yang artinya pemberian secara sukarela dan tidak ditentukan oleh aturan-aturan tertentu, baik itu mengenai jumlah ataupun jenis yang disedekahkan (Wati, 2013). Pada tradisi budaya daerah Jawa seperti di Jawa Tengah, masyarakat mengartikan tradisi sedekah bumi merupakan perayaan adat sebagai upaya mengungkapkan rasa syukur masyarakat yang ada disana. Sementara, menurut Hidayatulloh (2015) masyarakat di daerah itu juga menganggap bumi yang sebagai tempat tinggal mereka yang dimanfaatkan untuk kegiatan bercocok tanam yaitu merupakan sebagai suatu medianya, sehingga mereka dapat melaksanakan kegiatan panen dan hasil bumi yang sangat melimpah. Jadi masyarakat disana merasa perlu melaksanakan tradisi ini sebagai upaya mengungkapkan rasa syukur atas keselamatan dan rezeki yang diperoleh selama tinggal di bumi ini. 


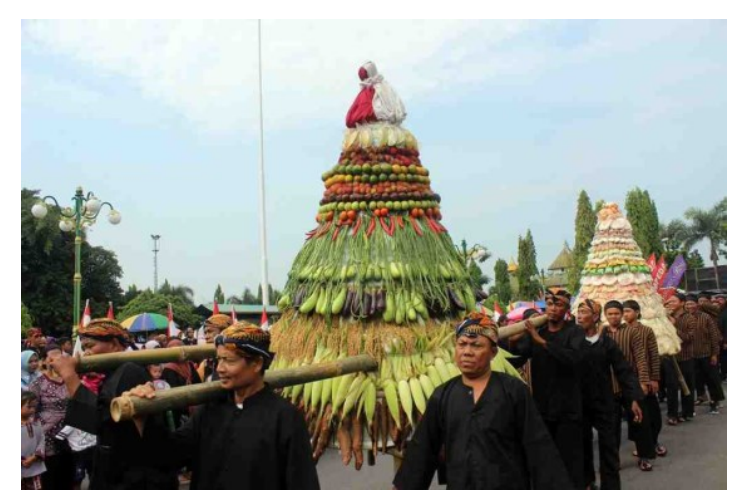

Gambar 1 Tradisi Sedekah Bumi

(Sumber: lpminvest.com, 2021)

Menurut Veralidiana (2010) dalam skripsinya tradisi sedekah bumi merupakan salah satu bentuk upacara tradisional yang dilakukan turun-temurun oleh masyarakat sejak masa nenek moyang orang Jawa pada zaman dahulu. Selain itu, tradisi ini memiliki arti yang lebih penting lagi yaitu merupakan upacara tradisional yang telah melekat dengan kultur (budaya) masyarakat Jawa sebagai simbol untuk melestarikan kearifan lokal khas yang dimiliki oleh masyarakat agraris ataupun nelayan yang berada di pulau Jawa. Bentuk persembahan kepada roh nenek moyang menjadi salah satu bentuk upacara keagamaan yang dilaksanakan dengan melakukan segala bentuk upacara atau selamatan bumi menggunakan berbagai jenis sesaji.

\section{Pelaksanaan Tradisi Sedekah Bumi}

Pelaksanaan tradisi sedekah bumi dalam tiap daerah berbeda-beda cara melakukannya perbedaan tersebut dapat terlihat dari ritual yang diadakan, pertunjukan serta sajian atau makanan yang dihidangkan dalam upacara tradisi sedekah bumi akan tetapi dalam segi tujuannya pelaksanaan tradisi sedekah bumi memiliki persamaan yaitu sama-sama mewujudkan rasa syukur masyarakat atas keselamatan dan segala rezeki yang diperoleh selama mereka menempati dan tinggal di bumi serta rasa syukur mereka akan keberhasilan panennya.

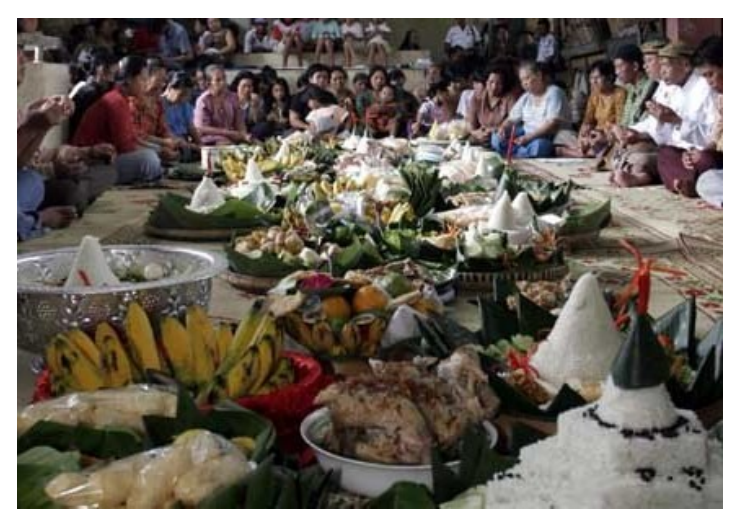

Gambar 2 Pelaksanaan Tradisi Sedekah Bumi (Sumber: joypardi.blogspot.com, 2021)

Pelaksanan tradisi sedekah bumi tiap daerah berbeda pada bulan pelaksanaannya sesuai dengan keyakinan masyarakat setempat bulan-bulan pelaksanaanya yaitu bulan Sura (kalender jawa) atau bulan Muharrah (kalender hijriyah), dan bulan safar. Menurut Bustomi (2019) dalam skripsinya waktu pelaksanaan tradisi sedekah bumi didesa Teras Bendung dilakukan pada bulan safar berdasarkan pertimbangan dan keyakinan masyarakat mengenai bulan safar masyarakat beranggapan bahwa bulan yang kurang baik, dibulan tersebut akan muncul berbagai bencana. Maka dari itu masyarakat yakin bahwa bulan safar inilah bulan yang tepat untuk melaksanakan tradisi sedekah bumi dengan memanjatkan do'a pada sang maha pencipta agar masyarakat selalu dalam lindungan sang maha pencipta dan diberi rahmat berupa kedamaian dan ketentraman. Menurut Nuraeni (2018) dalam skripsinya Pelaksanaan tradisi sedekah bumi dapat dibagi menjadi empat bagian, antara lain:

1. Persiapan $(\mathrm{H}-7)$

Pada saat (H-7) persiapan acara sedekah bumi sudah harus melakukan kegiatan musyawarah, untuk membahas berbagai macam hal seperti pembentukan pengurus atau penanggung jawab, penentuan tanggal pelaksanaan, menentukan besarnya iuran yang perlu dikumpulkan, dan memilih tempat untuk melaksanakan acara sedekah bumi tersebut.

2. Persiapan (H-1) 
Pada persiapan (H-1) acara sedekah bumi ada hal yang perlu dipersiapkan yaitu menyediakan syarat-syarat pokok acara sedekah bumi seperti kambing, ayam kampung bekakak, bubur sura, dan lain-lain.

3. Pra acara tradisi sedekah bumi,

Sebelum acara sedekah bumi dimulai biasanya dilakukan penyembelihan hewan kambing yang kemudian dilanjutkan dengan membakar ayam kampung dan meracik bubur sura, lalu menyiapkan sesaji dan juga berkat serta menyiapkan tempat untuk prosesi acara.

4. Prosesi acara sedekah bumi

Prosesi acara sedekah bumi adalah puncak dari dilaksanakannya acara sedekah bumi. Dengan melakukan kegiatan yang diawali dengan pembukaan dan dilanjutkan dengan memberikan kata sambutan, kemudian ikrar lalu membaca tahlil serta doa bersama. Baru setelah itu makan bersama-sama, kemudian membagikan daging kambing dan juga berkat, sampai terakhir membersihkan tempat sehabis dilaksanakannya acara sedekah bumi.

\section{Manfaat dan Nilai-Nilai Tradisi Sedekah Bumi dari Sudut Pandang Teori Fungsionalisme}

Dalam kegiatan perayaan tradisi sedekah bumi terdapat berbagai manfaat dan nilai-nilai yang terkandung didalamnya, Menurut Zainal (2014) nilai-nilai tersebut dapat dikaji dengan teori fungsionalisme yang di kemukakan oleh Emile Durkheim mengungkapkan teori fungsionalisme dapat diketahui sebagai fungsi ritual keagamaan yang sesungguhnya memberikan kesempatan kepada setiap anggota masyarakat untuk memperbaharui komitmen mereka kepada komunitas, agar mereka selalu ingat bahwasanya dalam keadaan apapun, mereka sendiri tak terlepas dari ketergantungan masyarakat. Ritual memiliki fungsi sosial sebagai upaya memperkuat rasa solidaritas di antara anggota masyarakat. Efek dari ritual yaitu ialah hadir dan bekerja secara bersamasama, dengan begitu kesatuan dan persatuan masyarakat dapat diperkuat dan solidaritas antar masing-masing anggota akan lebih meningkat pula. Adapun teori yang dikemukakan oleh Kontjaraningrat dalam Hidayat (2015) ia mengatakan masyarakat adalah kesatuan masyarakat yang berinteraksi berdasarkan adat istiadat yang sifatnya kontinyu serta terikat pada suatu identitas bersama.

Nilai nilai yang terkandung dalam tradisi sedekah bumi yang dikaji dari sudut pandang teori fungsionalisme antara lain yaitu:

1. Nilai akidah

Nilai aqidah ditunjukkan dalam hal ketika pembacaan doa pada saat prosesi acara berlangsung, berfungsi meyakini dan percaya bahwa rezeki hasil panen bumi yang melimpah semua itu pemberian dari Allah SWT.

2. Nilai ibadah

Ada dua nilai ibadah dalam tradisi sedekah bumi ini, yaitu ibadah antara manusia dengan Allah SWT dan ibadah antara manusia dengan manusia lainnya. Ibadah antara manusia dengan Allah SWT diperlihatkan dalam hal pembacaan ayat suci Al-Qur'an, pembacaan zikir \& salawat, serta pembacaan doa bersama ketika prosesi acara berlangsung. Sedangkan, ibadah antara manusia dengan manusia lain ditunjukkan dalam hal ketika saat makan bersama dan kemudian saling bertukar makanan masing-masing dari dibawa oleh para warga.

3. Nilai sosial, tradisi sedekah bumi memberikan ajaran agar saling menjaga dan menjalin silaturahmi antar satu sama lain. Hal tersebut jelas mengajarkan betapa penting arti silaturahmi karena pada zaman ini masih saja terdapat suatu komunitas masyarakat yang tidak mengenal antar satu sama lain hal itu dapat terjadi karena berbagai faktor, baik itu faktor pergaulan maupun faktor kesibukan.

4. Nilai budaya, dalam perayaan tradisi sedekah bumi ini diyakini oleh banyak 
masyarakat bahwa apabila perayaan ini tidak di lakukan maka akan membawa atau mendatangkan malapetaka bagi masyarakat, malapetaka tersebut berupa gagal panen, hama tanaman dan hewanhewan ternak meninggal dikarenakan terkena penyakit

5. Nilai filosofis, dalam perayaan tradisi sedekah bumi mengandung sebuah filosofis berupa interaksi sosial yang terjalin dalam masyarakat dan nantinya akan menumbuhkan sebuah persatuan dan kesatuan dalam masyarakat.

Dari nilai-nilai yang terkandung pada perayaan acara sedekah bumi tersebut dapat diambil sebuah sisi positif dan kebiasaankebiasan baik yang dapat diwariskan pada generasi-generasi penerus serta sebagai pedoman hidup dalam hidup beragama dan bermasyarakat guna mewujudkan sebuah kerukunan, kedamaian dan kesejahteraan yang makmur dan bahagia dalam hidup bersosial. Sejatinya manusia merupakan mahluk sosial yang membutuhkan bantuan manusia lainnya dalam menjalankan kehidupan, maka dari itu dibutuhkan sebuah sikap saling membantu, tolong menolong dan peduli terhadap sesama manusia.

\section{KESIMPULAN}

Tradisi sedekah bumi adalah sebuah perayaan adat yang ditujukan pada bumi sebagai bentuk rasa syukur dan wujud terima kasih masyarakat pada sang penciptanya. Tradisi sedekah bumi tersebut telah ada sejak zaman dahulu dan dilaksanakan secara turuntemurun. Tradisi ini berupa kegiatan selamatan setelah melakukan kegiatan panen karena dianggap sebagai upaya mewujudkan rasa syukur atas rezeki yang diterima. Selain itu, tradisi ini memiliki arti yang lebih penting yaitu merupakan upacara tradisional yang telah melekat dengan kultur (budaya) masyarakat Jawa sebagai simbol untuk melestarikan kearifan lokal khas yang dimiliki oleh masyarakat agraris ataupun nelayan yang berada di pulau Jawa.

Pelaksanaan tradisi sedekah bumi dibagi menjadi empat bagian diantaranya, yaitu persiapan (H-7), persiapan $(\mathrm{H}-1)$, pra acara tradisi sedekah bumi, dan prosesi acara tradisi sedekah bumi. Kemudian, dalam pelaksanaan tradisi sedekah bumi terdapat manfaat dan nilai-nilai yang terkandung didalamnya dan nilai-nilai tersebut dapat dikaji dengan teori fungsionalisme sebagai fungsi ritual keagamaan dan fungsi sosial. Nilai-nilai yang terkandung dalam tradisi sedekah bumi tersebut, antara lain nilai akidah, nilai ibadah, nilai sosial, nilai budaya, dan nilai filosofis. Dari nilai-nilai yang terkandung pada acara sedekah bumi dapat diambil hikmah dan sisi positif dan kebiasaan baik yang dapat diwariskan pada generasigenerasi penerus serta sebagai pedoman hidup dalam hidup beragama dan bermasyarakat guna mewujudkan sebuah kerukunan, kedamaian dan kesejahteraan yang makmur dan bahagia dalam hidup bersosial.

\section{DAFTAR PUSTAKA}

Bustomi. 2019. Makna Ritual Sedekah Bumi Kecamatan Lebak Wangi Kabupaten Serang - Banten Fakultas Ushuluddin Dan Adab Universitas Islam Negeri (Uin) Sultan Maulana Hasanuddin Banten $2019 \mathrm{M} / 1440 \mathrm{H}$.

Setyosari, H. P. 2016. Metode Penelitian Pendidikan \& Pengembangan (Edisi Keem). Prenada Media.

Hidayat, A. 2015. Pemanfaatan Pekarangan Model Kawasan.

Hidayatulloh, F. S. 2015. Sedekah Bumi Dusun Cisampih Cilacap. El-Harakah (Terakreditasi), 15(1), 1. https://doi.org/10.18860/el.v15i1.2669

Nazir, M. 1988. Metode Penelitian. Jakarta: Ghalia Indonesia.

Nuraeni, E. E. N., Pendidikan, J., Islam, A., Tarbiyah, F., \& Ilmu, D. A. N. 2018. 
Nilai-Nilai Pendidikan Islam Dalam

Tradisi Sedekah Bumi Di Dusun Cigintung.

Veralidiana, I. 2010. Jurusan Al-Ahwal AlSyakhshiyyah.

Wati, B. 2013. No Title. Jurnal Program Studi Pendidikan Bahasa Dan Sastra Jawa $U M P, 2(4)$.

Zainal, A. 2014. Sakral dan Profan dalam Ritual. Al-Izzah, 9(1), 61-71.

lpminvest.com. (2019, 22 Juli). Sedekah Bumi dan Tradisi Masyarakat Pati. Diakses pada Januari 2021, dari http://pminvest.com/2019/07/sedekahbumi-dan-tradisi-masyarakat-pati/

joypardi.blogspot.com. (2018, Oktober 30). Kenduri tradisi jawa, penuh dengan simbol dan filosofi. Diakses pada Januari 2021， dari https://joypardi.blogspot.com/2018/10/ kenduri-tradisi-jawa-penuhdengan.html 